\title{
Effect of Oxytetracycline-Hydrochloride on Phytoplasma Titer and Symptom Progression of the 16SrIV-D Phytoplasma in Cabbage Palms from Florida
}

\author{
Noemi Soto, Alessandra R. Humphries, De-fen Mou, Ericka E. Helmick, James P. Glover, and Brian W. Bahder ${ }^{\dagger}$ \\ Department of Entomology and Nematology, University of Florida - Fort Lauderdale Research and Education Center, Davie, FL \\ 33314
}

\begin{abstract}
Lethal bronzing (LB) is a phytoplasma disease of palms in Florida, U.S.A. Historically, the use of the antibiotic oxytetracycline-hydrochloride $(\mathrm{OTC}-\mathrm{HCl})$ was optimized to treat for LY, and currently label rates for OTC-HCl developed for LY are being used to treat palms preventatively against LB. Because of the economic impact of LB, assessing OTC- $\mathrm{HCl}$ against LB is essential for developing and optimizing management options for this disease. In this study, Sabal palmetto palms declining from LB were injected with OTC-HCl to assess efficacy on LB. Four groups of palms were selected that represented healthy palms, early symptomatic palms, palms with moderate symptoms, and palms with late-stage symptoms. Within each group, treatment palms injected

the control palms did. The early symptomatic palms that were treated had similar levels of phytoplasma to the control group but had much slower symptom development. Palms with moderate symptoms had no difference in titer between the treatment and the control group, but treated palms had much slower symptom development. Palms with late-stage symptoms showed no difference in phytoplasma titer or symptom progression between treated and control palms. These results suggest that label rates of OTC- $\mathrm{HCl}$ appear useful as a preventative against $\mathrm{LB}$, but once symptoms develop, label rates cannot cure palms. In the meantime, removal of symptomatic palms is recommended.
\end{abstract} with $\mathrm{OTC}-\mathrm{HCl}$ and a control group with no antibiotics were tested weekly by quantitative PCR for 1 year. For asymptomatic palms, treated palms never developed symptoms or tested positive, whereas one of
Keywords: antibiotics, palms, lethal bronzing, phytoplasma, oxytetracyclinehydrochloride
The antibiotic oxytetracycline-hydrochloride (OTC-HCl) is a common compound used to mitigate the symptoms and effects that phytoplasmas have on their associated host plants. This compound has demonstrated utility in a wide range of crops/plant hosts that include, but are not limited to, grapevines (Gribaudo et al. 2007), sugarcane (Distabanjong et al. 2016), almond (Chalak et al. 2005), and Chrysanthemum spp. (Chung and Choi 2002; Taloh et al. 2018). In addition to these plants, OTC-HCl has also been used as a management tool for control of the 16SrIV-A phytoplasma, the causal agent of lethal yellowing (LY), in coconut palms (McCoy 1972).

A preliminary study found that remission of symptoms caused by LY in coconut palms was achieved if 0.5 to 2.0 liters of OTC- $\mathrm{HCl}$ at 100 parts per million (ppm) was administered over a 24-h period (McCoy 1972). In this study, the OTC-HCl was introduced by drilling a hole in the trunk and injecting directly into the vascular system via a supply reservoir. Subsequently, two different formulations of OTC-HCl were compared, one stabilized with citric acid and the other with tartaric acid, resulting in remission of symptoms using the tartaric acid formulation but not the citric acid formulation (McCoy 1973). In addition, soil drenches of OTC-HCl failed to result in remission of LY symptoms in coconut palm (McCoy 1973). It was determined later that trunk injections resulted in the fastest uptake and longest retention of $\mathrm{OTC}-\mathrm{HCl}$ in the palm tissue (McCoy

${ }^{\dagger}$ Corresponding author: B. W. Bahder; bbahder@ufl.edu

Funding: This research was possible by funds obtained from various stakeholders by way of extension events and services. This project was also supported by Hatch project number 005539 .

The author(s) declare no conflict of interest.

Accepted for publication 14 April 2020.

C 2020 The American Phytopathological Society
1974). Following these findings, a lower limit of $3 \mathrm{ppm}(3 \mu \mathrm{g} / \mathrm{g})$ was established as being effective at symptom remission if 1 liter was administered over $24 \mathrm{~h}$ (Hunt et al. 1974). It was established subsequently that in field settings, a dose 1 to $3 \mathrm{~g}$ of OTC-HCl per $500 \mathrm{ml}$ $(2,000$ to $6,000 \mathrm{ppm})$ was effective as a preventative treatment in coconut palms (McCoy et al. 1976).

Current label rates for OTC-HCl injections allow for injections of $5 \mathrm{ml}$ at 1,000 ppm for a single palm on a quarterly basis as a preventative against palm-infecting phytoplasmas (Bahder and Helmick 2019). This amount is based on the label rate of commercially available OTC-HCl. It is unclear how this concentration and amount were determined due to previous studies requiring higher amounts and concentrations, but this is the currently used formulation in the urban environment to prevent infection of LY. All research conducted to date was done in coconut palms and evaluated effectiveness against the 16SrIV-A phytoplasma (LY). Historically, LY (16SrIV-A) was a significant threat to palms in the state of Florida; however, since 2008 , lethal bronzing (16SrIV-D) has emerged as a significant threat to various palms throughout the state; as of 2016, it seems to have replaced the 16SrIV-A phytoplasma (Bahder et al. 2019a). Although there is some overlap in the species susceptible to A and D subgroups, one species that appears highly susceptible to the 16SrIV-D phytoplasma is the cabbage palm (Sabal palmetto Walter) (Bahder et al. 2019a; Harrison et al. 2009). Interestingly, S. palmetto was never documented as a host of the 16SrIV-A phytoplasma (Bahder and Helmick 2018a). Because OTC-HCl is a broad-spectrum antibiotic, it is likely to impact the 16SrIV-D phytoplasma the same as it would the 16SrIV-A phytoplasma. However, due to the economic threat that LB poses to Florida, this is not an assumption that should go untested. In addition, the infection of different palm species by the 16SrIV-D phytoplasma versus the 16SrIV-A phytoplasma creates an impetus to evaluate label rates of OTC-HCl on the 16SrIV-D phytoplasma in a species that was not affected by LY under Florida conditions. Finally, anecdotal evidence from anonymous stakeholders (landscape and nursery personnel) documents inconsistent results 
for using $\mathrm{OTC}-\mathrm{HCl}$ as a preventative, because some palms have been receiving injections for longer than 1 year and in some instances still become infected (Bahder, unpublished data).

Recently, an outbreak of LB at the University of Florida Fort Lauderdale Research and Education Center (FLREC) was documented in a stand of $S$. palmetto and queen palms (Syagrus romanzoffiana Chamisso) (Bahder et al. 2018). Following the initial outbreak that occurred, further spread was documented (Bahder et al. 2019a), with more $S$. palmetto becoming infected. Due to the availability of actively spreading $16 \mathrm{SrIV}-\mathrm{D}$ phytoplasma and an abundance of $S$. palmetto infected by the 16 SrIV-D phytoplasma at the research unit displaying different stages of decline, an evaluation of the effect of OTC-HCl on the 16SrIV-D phytoplasma in S. palmetto was initiated.

The primary objective of this study was to evaluate the impact of OTC-HCl applied at the commercially available label rate on the 16SrIV-D phytoplasma in S. palmetto by measuring phytoplasma titer and symptom progression and/or remission. A secondary objective was to assess the capacity of label rates of $\mathrm{OTC}-\mathrm{HCl}$ to prevent new infections of the 16SrIV-D phytoplasma.

\section{Materials and Methods}

Field site and experimental design. The location of this experiment was the University of Florida FLREC in Davie, FL, U.S.A. Recently, an outbreak of LB at FLREC was documented (Bahder et al. 2018), and due to unrestricted access to an abundance of declining $S$. palmetto at various stages of decline, the situation provided optimal conditions for conducting field trials of OTC-HCl injections. After a visual survey, experimental palms were divided into four groups; group 1 consisted of $S$. palmetto that were asymptomatic and assumed healthy $(\mathrm{H})$, group 2 consisted of $S$. palmetto that demonstrated early symptoms (ES) of LB (approximately 25\% canopy discoloration), group 3 consisted of $S$. palmetto that demonstrated moderate symptoms (MS) (approximately 50\% canopy discoloration), and group 4 consisted of S. palmetto that demonstrated heavy, or late-stage, symptoms (LS) (>75\% canopy discoloration). Within each symptom group there was an untreated control to which no OTC-HCl was administered. In addition to these palms, there were 62 asymptomatic palms in the vicinity and, although they were not sampled or injected due to resource constraints, they were observed for symptoms throughout and after the study period. Aside from palms on FLREC property, a cohort $(n=6)$ of $S$. palmetto was present on the property of the Broward County Extension Office. These palms were healthy at the onset of the study and were injected with OTC- $\mathrm{HCl}$ and monitored for symptom development.

OTC-HCl injection. Commercially available OTC-HCl (Tree Saver, Royal Palm Beach, FL) at 39\% active ingredient was purchased and used for this study. OTC-HCl solution was prepared by mixing $3 \mathrm{~g}$ of OTC- $\mathrm{HCl}$ in $3 \mathrm{ml}$ of distilled water (approximately $1,000 \mathrm{ppm}$ ). Injection sites were created by drilling a $0.8-\mathrm{cm}$ hole with a power drill at the base of the trunk. The injection valve was inserted into the hole, and, using the commercially available injector, $3 \mathrm{ml}$ of solution was injected into the valve. Injections of OTC-HCl occurred on March 29, 2018, June 29, 2018, September 28, 2018, and January 4, 2019.

Palm sampling and DNA extraction. All palms were sampled by taking trunk tissue according to the method of Bahder and Helmick (2018b). Baseline data were generated by sampling each palm in the study 1 week prior to injection and verifying that asymptomatic palms tested negative by quantitative polymerase chain reaction (qPCR) and that symptomatic palms tested positive. Following the initial injection on March 29, 2018, all palms were sampled and tested weekly for 1 year, with the last sample date occurring on March 29, 2019. Symptom data were collected monthly by visual inspection, and each palm was photographed using a Nikon COOLPIX B700. Trunk tissue was stored at $-20^{\circ} \mathrm{C}$ until processing. For each sample, $1 \mathrm{~g}$ of trunk tissue was macerated in guanidine buffer (guanidine thiocyanate, $4 \mathrm{M}$ and $3 \mathrm{M}$; sodium acetate, $0.2 \mathrm{M}$ and $0.5 \mathrm{M}$; EDTA, $0.25 \mathrm{M}$; PVP-40, $0.0006 \mathrm{M}$ ) in a BioReba extraction bag using the HOMEX6 tissue homogenizer. Lysate was extracted using the Plant Mini Kit (Qiagen) according to the manufacturer's instructions. Eluate was quantified subsequently using a NanoDrop Lite (ThermoFisher Scientific, Waltham, MA) and diluted to $25 \mathrm{ng} / \mu \mathrm{l}$ of total DNA.

qPCR assay parameters and phytoplasma quantification. All qPCR reactions were performed on a QuantStudio 6 Flex RealTime PCR System (Applied Biosystems) and consisted of $10 \mu \mathrm{l}$ of TaqMan Universal Master Mix II with uracil- $N$-glycoslyase (UNG), $10 \mu \mathrm{M}$ of each LY16S-LSF and -LSR primer, $10 \mu \mathrm{M}$ of LY16S probe, $10 \%$ PVP, $25 \mathrm{ng}$ of gDNA $(1 \mu \mathrm{l})$, and sterile $\mathrm{dH}_{2} \mathrm{O}$ to a final volume of $20 \mu$ l. Córdova et al. (2014) designed both primers, LY16-LSF/LY16-LSR, and probe used in this assay. Reactions were subject to the following cycling parameters: $95^{\circ} \mathrm{C}$ for $10 \mathrm{~min}$, followed by 35 cycles of $95^{\circ} \mathrm{C}$ for $30 \mathrm{~s}, 60^{\circ} \mathrm{C}$ for $60 \mathrm{~s}$, and $72^{\circ} \mathrm{C}$ for $30 \mathrm{~s}$. Data were collected and analyzed using the QuantStudio Real-Time PCR Software version 1.3 (Life Technologies). All qPCR assays were run in triplicates per specimen. Standard PCR, using primers LY16-LSF/LY16-LSR (Córdova et al. 2014), was used for amplification of gDNA from sample Spa-12 (Bahder et al. 2018), which had tested positive for LB. Each PCR contained 5x GoTaq Flexi Buffer, $25 \mathrm{mM} \mathrm{MgCl} 2,10 \mathrm{mM}$ dNTPs, $10 \mathrm{mM}$ each primer, $10 \%$ PVP-40, $2.5 \mathrm{U}$ of GoTaq Flexi DNA Polymerase, and sterile $\mathrm{dH}_{2} \mathrm{O}$ to a final volume of $25 \mu \mathrm{l}$. Thermocycling parameters were as follows: $94^{\circ} \mathrm{C}$ for $1 \mathrm{~min}$ initial denaturation, followed by 35 cycles of $94^{\circ} \mathrm{C}$ for $30 \mathrm{~s}, 60^{\circ} \mathrm{C}$ for $30 \mathrm{~s}, 72^{\circ} \mathrm{C}$ for $30 \mathrm{~s}$, and a final extension of $72^{\circ} \mathrm{C}$ for $5 \mathrm{~min}$. Three microliters of each product was

Table 1. Baseline test for all Sabal palmetto tested weekly to monitor oxytetracycline-hydrochloride (OTC-HCl) efficacy ${ }^{\mathrm{a}}$

\begin{tabular}{lccc}
\hline Palm no. & Symptoms & Treatment & Results $(q u a n t i t y$, Tm) \\
\hline Spa-8 & None & OTC-HCl & $0,69.4$ \\
Spa-24 & None & OTC-HCl & $0,70.3$ \\
Spa-40 & None & Control & $0,70.8$ \\
Spa-6 & Early $(\approx 25 \%$ canopy loss $)$ & OTC-HCl & $811,587,80.4$ \\
Spa-33 & Early $(\approx 25 \%$ canopy loss $)$ & OTC-HCl & $1,488,437,80.4$ \\
Spa-38 & Early $(\approx 25 \%$ canopy loss $)$ & OTC-HCl & $166,200,80.4$ \\
Spa-39 & Early $(\approx 25 \%$ canopy loss $)$ & Control & $117,554,80.4$ \\
Spa-26 & Moderate $(\approx 50 \%$ canopy loss $)$ & OTC-HCl & $347,089,80.4$ \\
Spa-32 & Moderate $(\approx 50 \%$ canopy loss $)$ & OTC-HCl & $490,558,80.4$ \\
Spa-36 & Moderate $(\approx 50 \%$ canopy loss $)$ & Control & $359,076,80.4$ \\
Spa-31 & Late $(>75 \%$ canopy loss $)$ & OTC-HCl & $478,179,80.4$ \\
Spa-34 & Late $(>75 \%$ canopy loss $)$ & OTC-HCl & $1,128,732,80.4$ \\
Spa-35 & Late $(>75 \%$ canopy loss $)$ & Control & $599,681,80.4$ \\
16 SrIV-A $(+)$ & N/A & N/A & N/A, 80.0 \\
16 SrIV-D $(+)$ & N/A & N/A & N/A, 80.4 \\
Healthy palm & N/A & N/A & N/A, 67.1 \\
Water control & N/A & N/A & N/A, 61.0 \\
\hline
\end{tabular}

${ }^{\mathrm{a}} \mathrm{Tm}=$ melting temperature of the amplicon, and $\mathrm{N} / \mathrm{A}=$ not applicable. 
electrophoresed on a $1.5 \%$ agarose gel stained with GelRed Nucleic Acid Gel Stain (Biotium, Hayward, CA) and visualized using ultraviolet transillumination. PCR products were cloned using a TOPO TA Cloning Kit into vector pCR 2.1-TOPO (Invitrogen) per the manufacturer's protocol. The cloning constructs were transformed into TOPO One Shot Chemically Competent E. coli cells and plated on LB plates containing $50 \mu \mathrm{g} / \mathrm{ml}$ of kanamycin. Plates were incubated overnight at $37^{\circ} \mathrm{C}$, and transformed colonies were chosen for colony PCR using primers LY16-LSF/LY16-LSR (Córdova et al. 2014) to verify that they contained the correct insert. Clones with the insert of the correct size were incubated on a shaker overnight in $20 \mathrm{ml}$ of LB broth with $50 \mu \mathrm{g} / \mathrm{ml}$ of kanamycin. Plasmids were extracted using a QIAprep Spin Miniprep Kit (Qiagen) per the manufacturer's protocol. Plasmid concentrations were quantified using a NanoDrop Lite Spectrophotometer (ThermoFisher Scientific). Tenfold serial dilutions were created, $10^{8}$ to $10^{3}$, for use as standards in the qPCR assay. Additionally, melt curve analysis was performed using the protocol outlined by Bahder et al. (2017) to confirm the 16SrIV-D identity of the isolates in this study.

PCR parameters and DNA sequence analysis. Amplification of phytoplasma from gDNA was conducted using a standard nested-PCR assay. Primary amplification of gDNA was performed using forward primer P1m (Harrison et al. 2008) and reverse primer LY16S-23R (Harrison et al. 2002), followed by nested-PCR assay using forward primer LY16Sf2 and reverse primer LY16-23Sr2 (Harrison et al. 2008). Each primary-PCR reaction contained $50 \mathrm{ng}$ of gDNA as a DNA template, $1 \mathrm{U}$ of Taq DNA Polymerase (New England Biolabs, Ipswich, MA), $0.125 \mathrm{mM}$ of each dNTP, $50 \mathrm{ng}$ each of forward and reverse primers, $1.5 \mathrm{mM} \mathrm{MgCl}_{2}$ in a standard PCR buffer, and sterile $\mathrm{dH}_{2} \mathrm{O}$ to a final volume of $50 \mu \mathrm{l}$. The
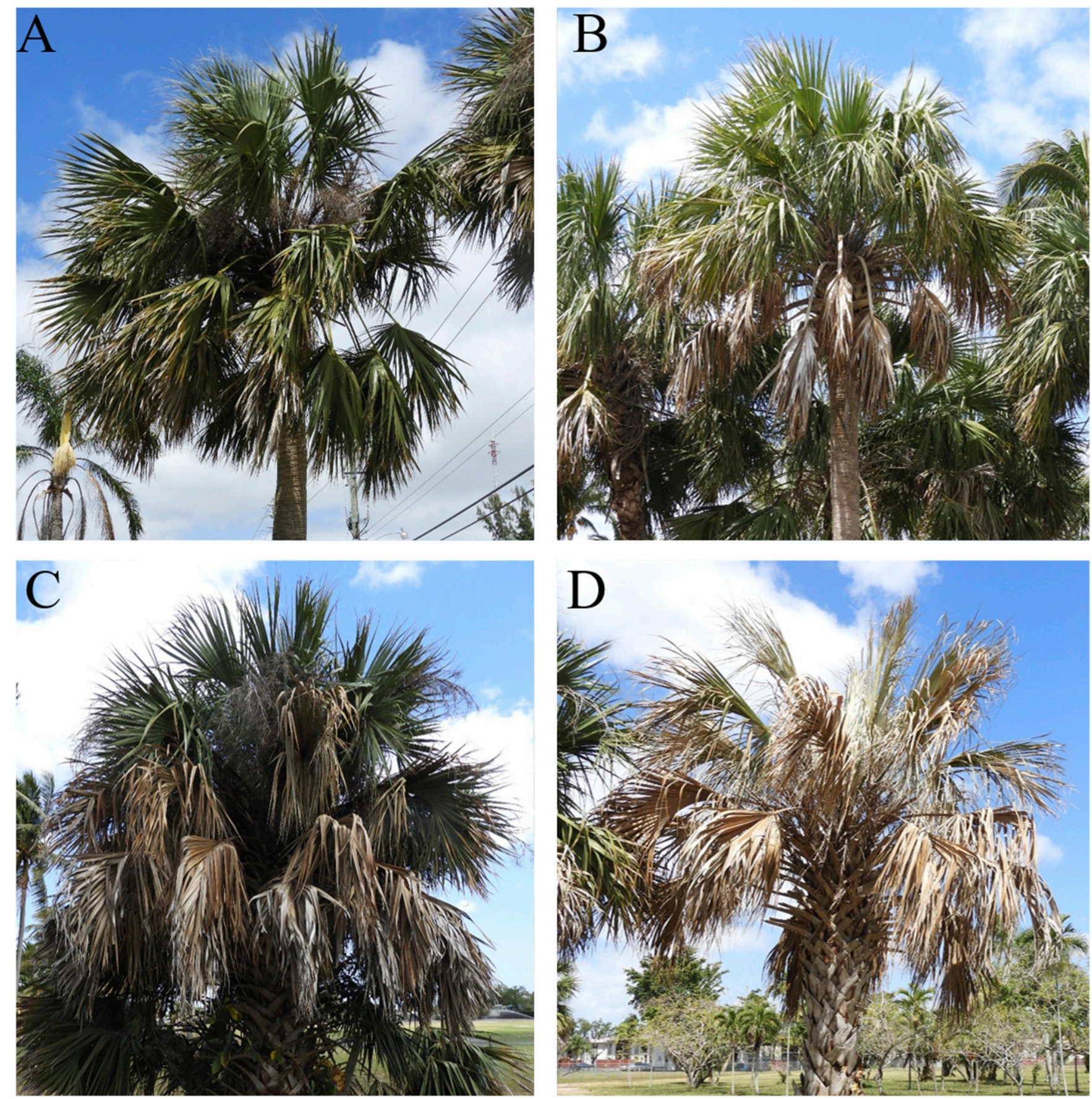

Fig. 1. Specimens of Sabal palmetto representing symptom stages used for assessing the label rate of oxytetracycline-hydrochloride on phytoplasma titer and symptom progression: $\mathbf{A}$, healthy/asymptomatic; $\mathbf{B}$, early symptoms; $\mathbf{C}$, moderate symptoms; and $\mathbf{D}$, late symptoms. 
primary-PCR cycling conditions were as follows: initial denaturation, $95^{\circ} \mathrm{C}$ for $60 \mathrm{~s}$, followed by 34 cycles of denaturation at $95^{\circ} \mathrm{C}$ for $30 \mathrm{~s}$, annealing at $60^{\circ} \mathrm{C}$ for $60 \mathrm{~s}$, extension at $72^{\circ} \mathrm{C}$ for $120 \mathrm{~s}$, and a final extension of $72^{\circ} \mathrm{C}$ for $8 \mathrm{~min}$.

For the nested-PCR assay, using primers LY16Sf2/LY16-23Sr2, the primary $\mathrm{P} 1 \mathrm{~m} / \mathrm{LY} 16 \mathrm{~S}-23 \mathrm{R}$ products were diluted $1: 10$, and $2 \mu \mathrm{l}$ of this dilution was used as the nested-PCR template using the same PCR components and ratios as for the primary PCR. The nested-PCR cycling conditions were as follows: initial denaturation, $94^{\circ} \mathrm{C}$ for 120 $\mathrm{s}$, followed by 34 cycles of denaturation at $94^{\circ} \mathrm{C}$ for $60 \mathrm{~s}$, annealing at $60^{\circ} \mathrm{C}$ for $120 \mathrm{~s}$, extension at $72^{\circ} \mathrm{C}$ for $3 \mathrm{~min}$, and a final extension of $72^{\circ} \mathrm{C}$ for $7 \mathrm{~min}$.

For each PCR assay, $10 \mu \mathrm{l}$ of the resulting PCR amplifications were electrophoresed on a $1 \%$ agarose gel, stained with GelRed (Biotium), and visualized using UV transillumination. Amplified products from the nested-PCR reaction were purified using ExoSAP-IT PCR Product Cleanup Reagent (ThermoFisher Scientific) per the manufacturer's protocol. The cleaned PCR products were sent to
Eurofins Diagnostics for sequencing. Resulting sequences were assembled, visually inspected, corrected for sequencing errors using DNA Baser version 4.36 (Heracle Biosoft), and then aligned using MEGA7 (Kumar et al. 2016). All sequences were identified as 16S rDNA phytoplasma sequences via nucleotide BLAST on the NCBI website (https://blast.ncbi.nlm.nih.gov/Blast.cgi).

\section{Results}

Specimen selection and confirmation of infection. A total of 13 individual palms were identified for use in the study (Table 1). Of these, three individuals appeared healthy and did not display any observable symptoms (Fig. 1A), four individuals displayed early symptoms (Fig. 1B), three individuals displayed moderate symptoms (Fig. 1C), and three individuals displayed severe symptoms (Fig. 1D). All three individuals appearing asymptomatic tested negative for the 16SrIV-D phytoplasma to establish the baseline dataset (Table 1). Additionally, all palms displaying symptoms tested positive for the 16SrIV-D phytoplasma based on the melting temperature of the

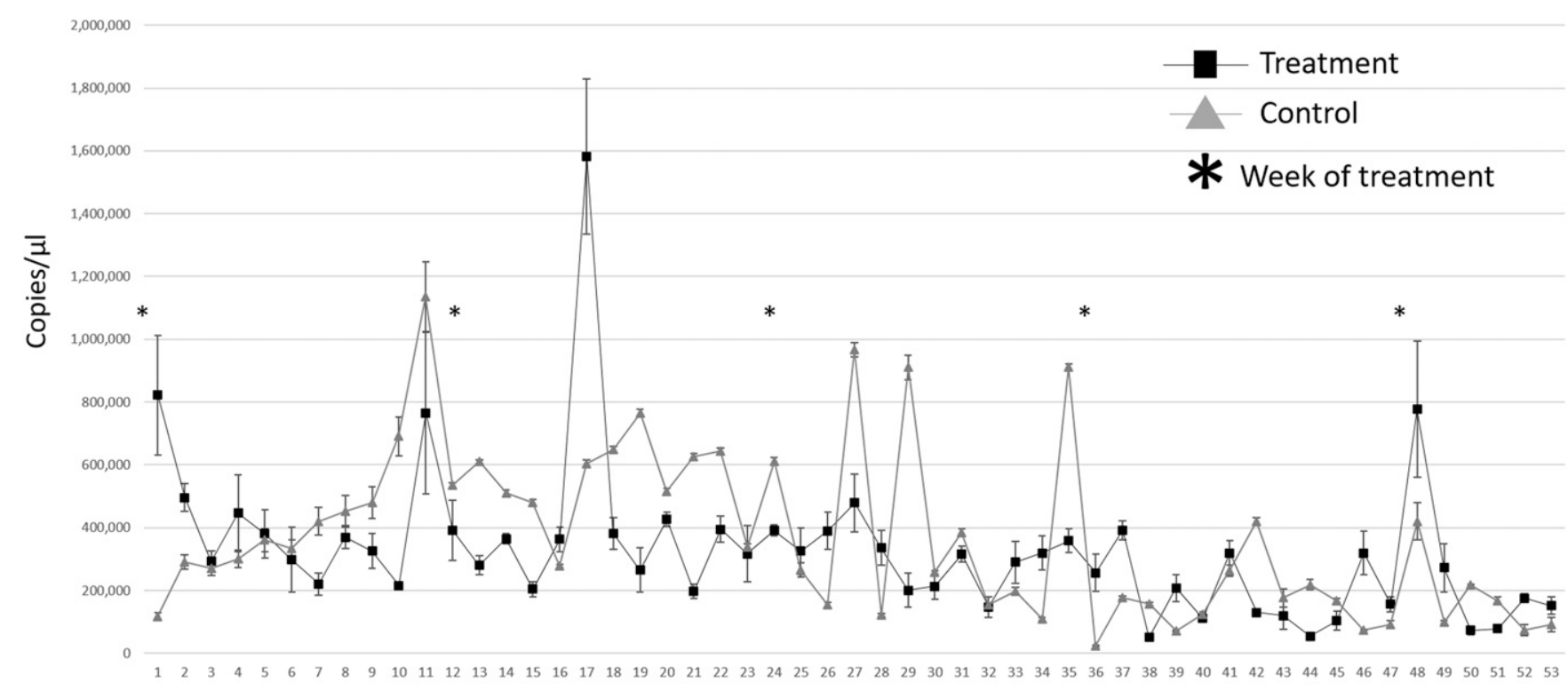

Week No.

Fig. 2. Average phytoplasma titer in early symptomatic Sabal palmetto throughout the study period.

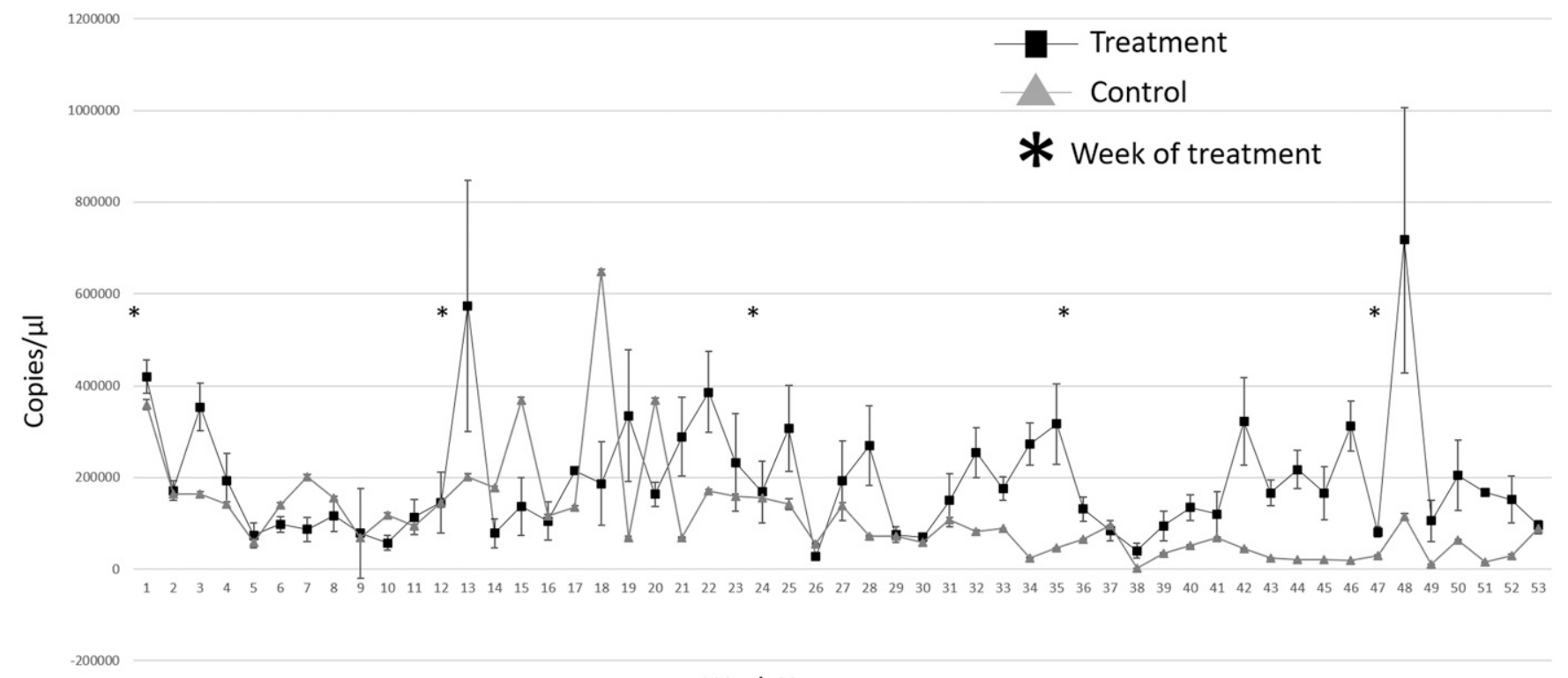

Week No.

Fig. 3. Average phytoplasma titer in moderate symptomatic Sabal palmetto throughout the study period. 
amplicon matching positive controls of the 16SrIV-D relative to the 16SrIV-A phytoplasma (Table 1).

OTC-HCl effect on phytoplasma titer. All $\mathrm{H}$ palms at the onset of the study tested negative and were injected with $\mathrm{OTC}-\mathrm{HCl}$ quarterly. They consistently tested negative throughout the study period. The control $\mathrm{H}$ palm did not develop symptoms during the study period and continually tested negative. In the ES palms, there was not a noticeable difference between the phytoplasma titer in the treatment group (injected with OTC-HCl) and the control group (no OTC- $\mathrm{HCl}$ injection). Phytoplasma titer in the ES palms fluctuated over time in a similar pattern between treatment and control palms and had comparable levels of phytoplasma, indicating there was no visible effect of OTC-HCl on phytoplasma titer in the trunk of the infected palms (Fig. 2). Average titer of phytoplasma in treated ES palms was $326,730 \pm 33,056$ copies $/ \mu 1$, whereas control ES palms had on average $367,714 \pm 36,066$ copies/ $\mu$ l across the entire study period. In the MS palms there was not a noticeable difference in phytoplasma titer between treated palms and control palms. Throughout the study period treated and control MS palms exhibited fluctuations in phytoplasma titer with comparable levels of phytoplasma between treated and control palms in the trunk (Fig. 3). The average phytoplasma titer for treated MS palms was $192,341 \pm 18,055$ copies/ $\mu 1$ across the

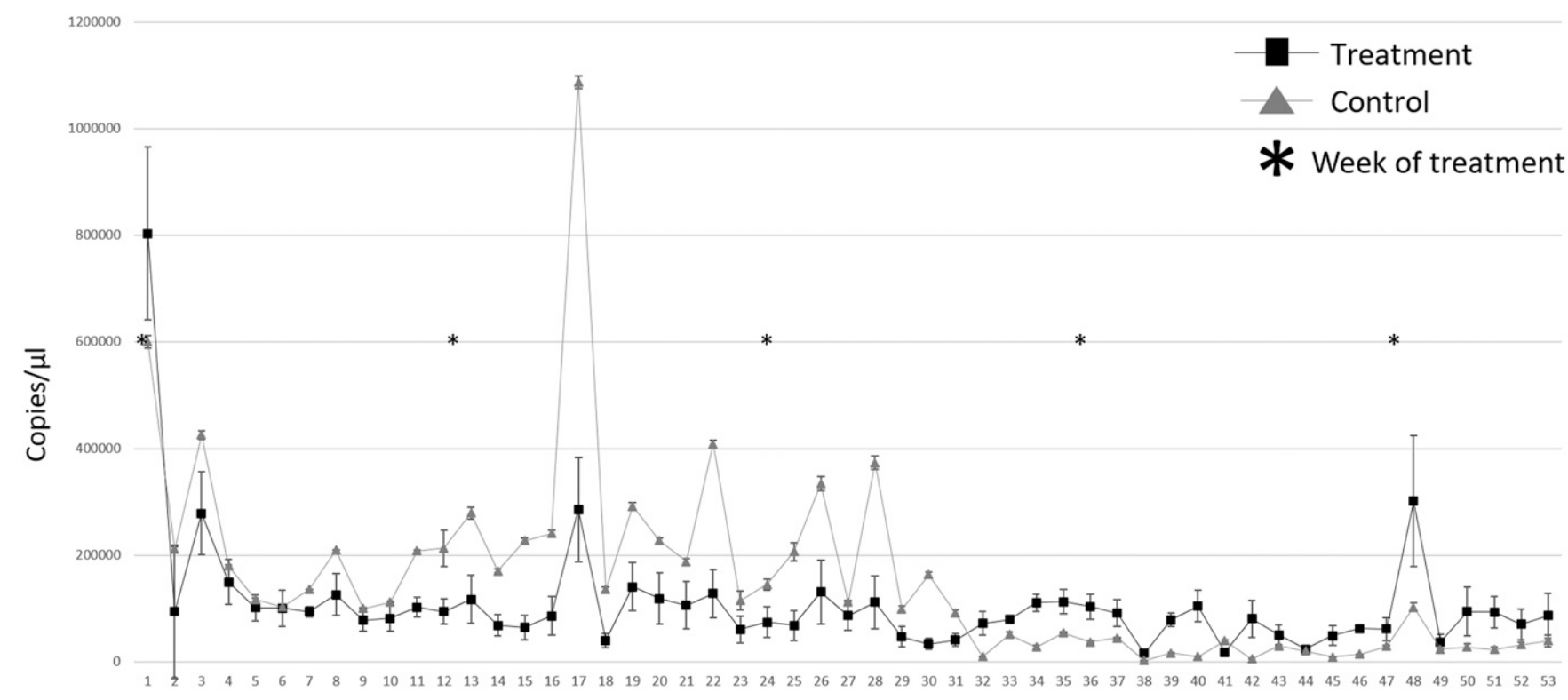

Week No.

Fig. 4. Average phytoplasma titer in late symptomatic Sabal palmetto throughout the study period.
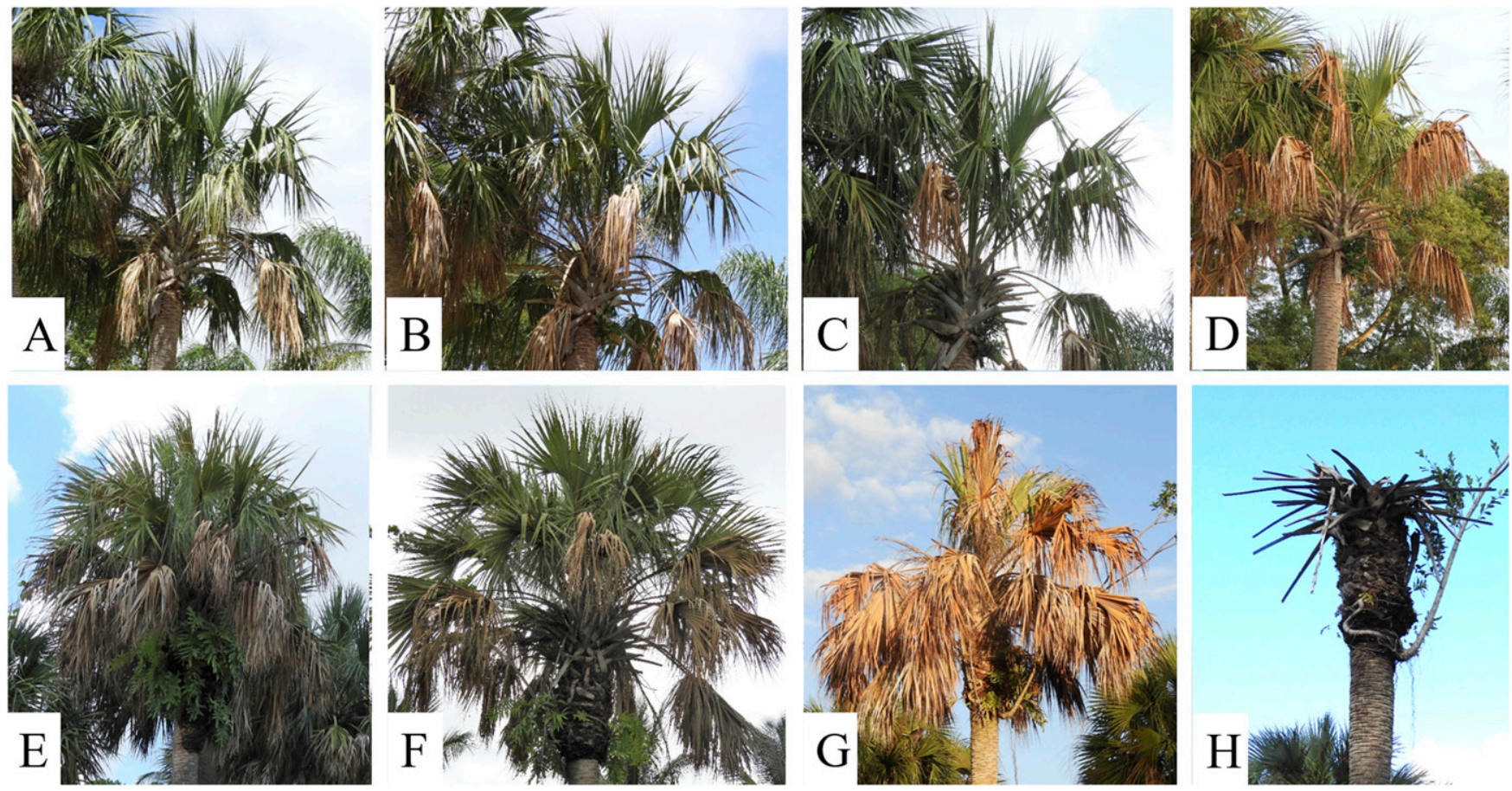

Fig. 5. Symptom progression of lethal bronzing in oxytetracycline-hydrochloride treated $(\mathbf{A}$ to $\mathbf{D})$ and control Sabal palmetto ( $\mathrm{E}$ to $\mathrm{H})$ with early symptoms on a quarterly basis over a 12-month period. 
entire study period, whereas control MS palms had on average $115,492 \pm 15,376$ copies/ $\mu l$ across the entire study period. In the LS palms, there was not a noticeable difference between phytoplasma titer in the treatment group and the control group. Phytoplasma titer in the LS palms fluctuated over time in a similar pattern between treatment and control palms and had comparable levels of phytoplasma, indicating there was no visible effect of OTC-HCl on phytoplasma titer in the trunk of the infected palms (Fig. 4). The average phytoplasma titer for treated LS palms was $107,916 \pm 15,651$ copies/ $\mu l$ across the entire study period, whereas control LS palms had on average 154,160 $\pm 25,304$ copies/ $\mu 1$ across the entire study period.

OTC-HCl effect on symptom progression. For the $\mathrm{H}$ palms that were asymptomatic and tested negative for $\mathrm{LB}$, both the treatment palms $(n=3)$ and control palm $(n=1)$ did not develop any symptoms throughout the study period. However, 3 months after the study

Table 2. Lethal bronzing (LB) disease symptom progression data for oxytetracycline-hydrochloride $(\mathrm{OTC}-\mathrm{HCl})$ treated Sabal palmetto displaying early symptoms $^{\mathrm{a}}$

\begin{tabular}{lcccc}
\hline & \multicolumn{3}{c}{ Percentage (\%) of canopy symptomatic for LB } \\
\cline { 2 - 5 } Months postinjection & Spa-6 $^{\mathbf{T}}$ & Spa-33 $^{\mathbf{T}}$ & Spa-38 $^{\mathbf{T}}$ & Spa-39C $^{\mathbf{C}}$ \\
\hline 1 & 20 & 24 & 22 & 22 \\
2 & 22 & 24 & 20 & 25 \\
3 & 38 & 22 & 22 & 39 \\
4 & 20 & 25 & 22 & $67^{*}$ \\
5 & 20 & 29 & 25 & 88 \\
6 & 19 & 39 & 32 & 95 \\
7 & 20 & 35 & 30 & 100 \\
8 & 20 & 40 & 40 & 100 \\
9 & 34 & 45 & 40 & 100 \\
10 & 34 & $45^{*}$ & $55^{*}$ & 100 \\
11 & 45 & 67 & 89 & 100 \\
12 & 53 & 85 & 100 & 100 \\
\hline
\end{tabular}

$\mathrm{a} \mathrm{T}^{\mathrm{T}}=$ palm treated with OTC-HCl; ${ }^{\mathrm{C}}=$ control palm with no OTC-HCl; and $*=$ spear leaf collapse/palm death.

period ended and OTC- $\mathrm{HCl}$ injections were stopped, the control $\mathrm{H}$ palm began to develop symptoms and tested positive for the 16SrIV-D phytoplasma (data not shown). For the ES treatment palms, symptoms developed slower than in the control ES palms (Fig. 5) with the majority of the canopy still green and the spear leaf present at 6 months, whereas the spear leaf had collapsed and the majority of the canopy was dead in the control ES palms (Table 2; Fig. 5). Symptom progression in MS treatment palms also was slower than observed in control palms (Fig. 6). In the control MS palms, at 3 months into the study, complete canopy loss and spear leaf collapse was observed, whereas the treated palms still had about half the canopy symptomatic, and the spear leaf was still intact, the same as observed at the beginning of the study (Table 3, Fig. 6). For the LS palms, there was not a noticeable difference in symptom progression between treated and control palms. All LS palms lacked a spear leaf but had some green foliage at the onset of the study and declined at

Table 3. Lethal bronzing (LB) disease symptom progression data for oxytetracycline-hydrochloride $(\mathrm{OTC}-\mathrm{HCl})$ treated Sabal palmetto displaying moderate symptoms ${ }^{\mathrm{a}}$

\begin{tabular}{lccc}
\hline & \multicolumn{3}{c}{ Percentage (\%) of canopy symptomatic for LB } \\
\cline { 2 - 4 } Months postinjection & Spa-26 $^{\mathbf{T}}$ & Spa-32 $^{\mathbf{T}}$ & Spa-36 $^{\mathbf{C}}$ \\
\hline 1 & 51 & 45 & 45 \\
2 & 56 & 59 & $98^{*}$ \\
3 & 54 & 54 & 100 \\
4 & 60 & 59 & 100 \\
5 & $60^{*}$ & $59^{*}$ & 100 \\
6 & 76 & 70 & 100 \\
7 & 85 & 80 & 100 \\
8 & 100 & 100 & 100 \\
9 & 100 & 100 & 100 \\
10 & 100 & 100 & 100 \\
11 & 100 & 100 & 100 \\
12 & 100 & 100 & 100 \\
\hline a T & = palm treated with OTC-HCl; ${ }^{\text {C }}=$ control palm with no OTC-HCl; and \\
$*$ & = spear leaf collapse/palm death.
\end{tabular}
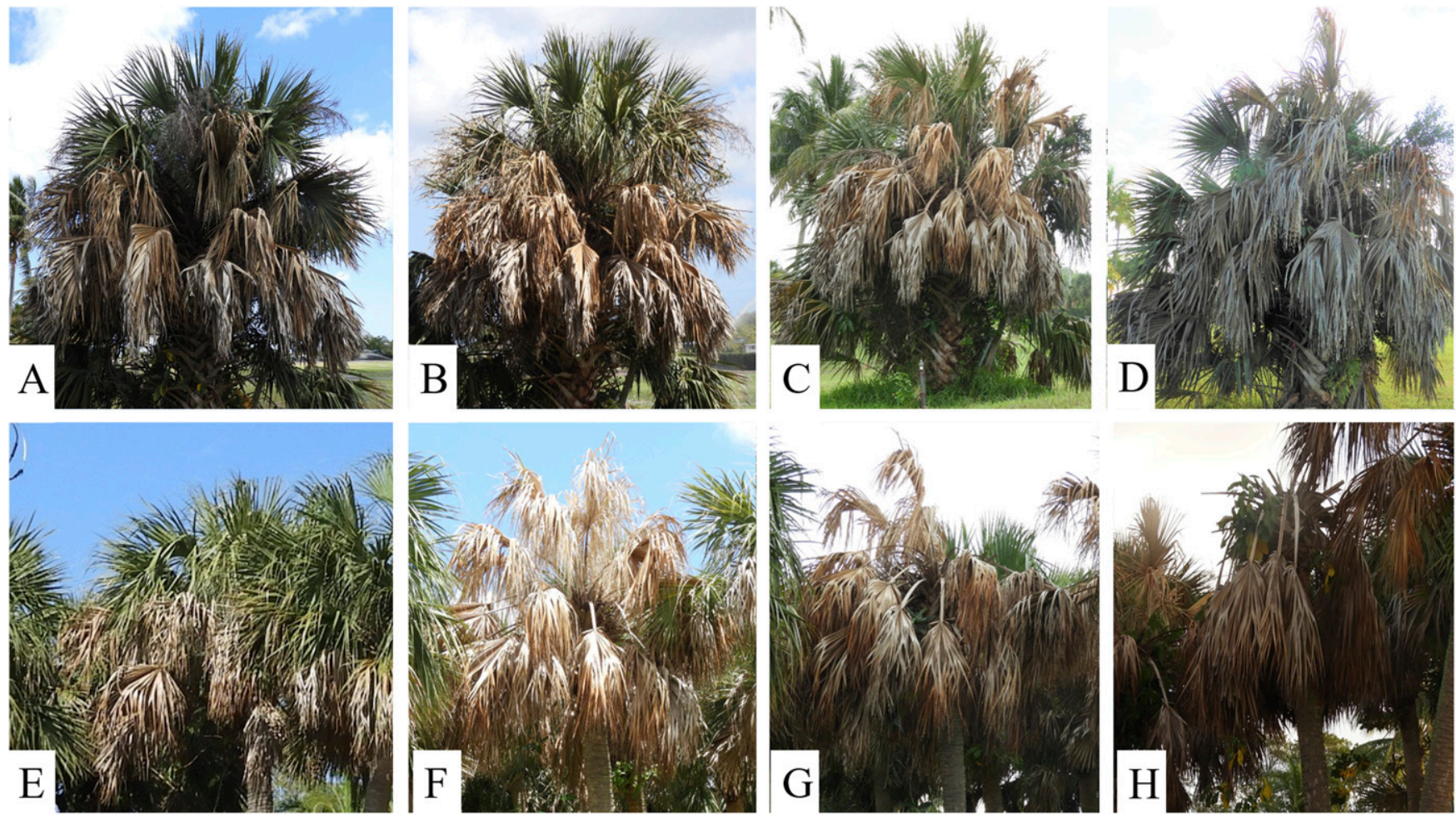

Fig. 6. Symptom progression of lethal bronzing in oxytetracycline-hydrochloride treated $(\mathbf{A}$ to $\mathbf{D})$ and control Sabal palmetto $(\mathrm{E}$ to $\mathrm{H})$ with moderate symptoms on a quarterly basis over a 12 -month period. 
similar rates (Table 4; Fig. 7). None of the six palms on the adjacent property (labeled EXT_1 through EXT_6) that were injected with OTC-HCl using the same protocol as those on FLREC developed symptoms during or after the study period ( 9 months). Of the 62 palms that were asymptomatic at the beginning study and adjacent to experimental palms, 25 developed symptoms approximately 6 to 9 months into the study period.

\section{Discussion}

These results represent the first attempt to assess the efficacy of OTC-HCl against the 16SrIV-D phytoplasma in Florida palms. Under the local conditions, the label rate of OTC-HCl that is commercially available and is injected on a quarterly basis is not sufficient to obtain symptom remission or decline in phytoplasma titer in infected palms. Based on lack of symptom development during the study period and negative qPCR results for all healthy palms that were injected to prevent infection, it appears that OTC- $\mathrm{HCl}$ can be

Table 4. Lethal bronzing (LB) disease symptom progression data for oxytetracycline-hydrochloride $(\mathrm{OTC}-\mathrm{HCl})$ treated Sabal palmetto displaying late symptoms $^{\mathrm{a}}$

\begin{tabular}{lccc}
\hline & \multicolumn{3}{c}{ Percentage (\%) of canopy symptomatic for LB } \\
\cline { 2 - 4 } Months postinjection & Spa-31 $^{\mathbf{T}}$ & Spa-34 $^{\mathbf{T}}$ & Spa-35 \\
\hline 1 & 75 & $95^{*}$ & $90^{*}$ \\
2 & 85 & 100 & 100 \\
3 & 90 & 100 & 100 \\
4 & $92^{*}$ & 100 & 100 \\
5 & 100 & 100 & 100 \\
6 & 100 & 100 & 100 \\
7 & 100 & 100 & 100 \\
8 & 100 & 100 & 100 \\
9 & 100 & 100 & 100 \\
10 & 100 & 100 & 100 \\
11 & 100 & 100 & 100 \\
12 & 100 & 100 & 100 \\
\hline
\end{tabular}

${ }^{\text {a T }}=$ palm treated with OTC-HCl; ${ }^{\mathrm{C}}=$ control palm with no OTC-HCl; and $*=$ spear leaf collapse/palm death. useful as a preventative treatment in cabbage palms. It is important to note that various stakeholders have confirmed that palms being injected preventatively for over 1 year have still contracted LB. Because of this, it is possible that $\mathrm{OTC}-\mathrm{HCl}$ as a preventative is not $100 \%$ effective and could be dependent on a variety of environmental factors (health of the palm, pathogen amount during exposure, or local climate conditions). Another possibility for infections occurring in preventatively injected palms is that many landscaping personnel will inject multiple times into the same hole in the trunk. Over time, as the wounded vascular tissue in the trunk desiccates, uptake of any injected substance may be reduced drastically. Regardless, under local conditions in S. palmetto, it appears preventative injections of OTC-HCl were successful in that none of the treated palms developed symptoms or tested positive during the study period in spite of documented active spread of the pathogen (Bahder et al. 2018) at the site, whereas 13 untreated palms developed symptoms. Due to the unknown nature of the insect vector and a lack of a reliable transmission assays or means to inoculate palms in the field or greenhouse, controlled experiments that definitively prove the efficacy of $\mathrm{OTC}-\mathrm{HCl}$ to prevent infection are not possible currently.

Although OTC-HCl injections did not stop or reverse symptoms, in palms with early and moderate symptoms of the LB, the symptom progression was much slower when compared with infected palms that were not injected with OTC-HCl. These results indicate that the OTC-HCl injected is having some effect on the phytoplasma in the palms, but the effect is not strong enough to reverse symptoms or eradicate the infection. In palms exhibiting late symptoms of LB, no difference was observed between treated and nontreated palms for symptom progression. This is likely because at the time of injection the spear leaf had collapsed, killing the palm so that no growth was occurring. Although it is encouraging that $\mathrm{OTC}-\mathrm{HCl}$ can slow symptoms at label rates, it is not recommended to utilize this practice, because although symptoms may have slowed significantly, the palm still has detectable levels of phytoplasma. It was found that the 16SrIV-D phytoplasma was restricted to the spear leaf in infected S. palmetto (Bahder et al. 2019b) but absent in other leaves in the canopy. Preventing collapse of the spear leaf or significantly delaying the canopy collapse is increasing the time the amount of available inoculum is present in the environment, also increasing the probability
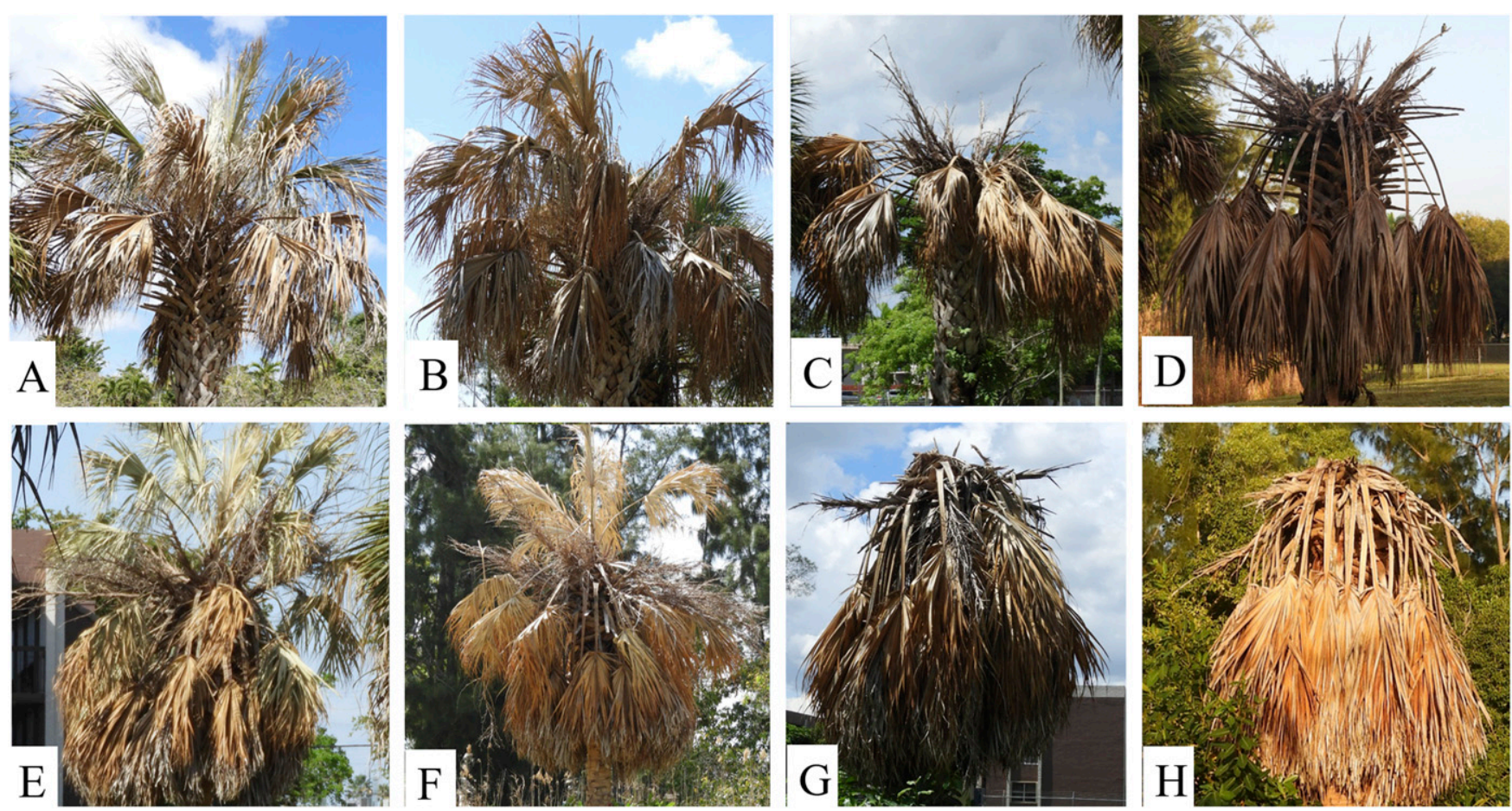

Fig. 7. Symptom progression of lethal bronzing in oxytetracycline-hydrochloride treated $(\mathbf{A}$ to $\mathbf{D})$ and control Sabal palmetto $(\mathbf{E}$ to $\mathrm{H})$ with late symptoms on a quarterly basis over a 12-month period. 
that an insect vector can acquire the phytoplasma and spread the disease, potentially exacerbating disease spread. Also, if the decline is delayed long enough, it may be possible for the phytoplasma to invade other green leaves in the canopy, exponentially increasing the probability of further spread. It is presumed that the lack of phytoplasma in leaves not attached to the meristem observed by Bahder et al. (2019b) is because the palm dies so quickly that the pathogen does not have time to colonize this tissue, but if the decline is delayed it may allow enough time for the phytoplasma to invade the tissue, creating more opportunity for insect vectors to acquire the pathogen. Although there was a clear difference in symptom progression between treatments and controls, there was no observable difference in phytoplasma titer between OTC-HCl injected palms and controls. This interesting observation is likely due to the translocation of the OTC-HCl into the palm, where it acts on phytoplasma in the meristem and near the crown, and not low on the trunk where sampling took place. This is supported by findings of McCoy (1976) that only trace amounts of OTC-HCl could be detected in the roots and trunk at various heights. It would be expected that if sampling occurred higher on the trunk, just below the crown, a significant difference would have been observed in phytoplasma between treatment and control palms, but due to the height of the palms, this region was inaccessible.

Interestingly, a higher titer of phytoplasma was documented in the palms with early symptoms. The presumed latent period for LB in $S$. palmetto is approximately 4 months (Bahder et al. 2018). It is presumed that during this time, the phytoplasma is moving throughout the vascular network, replicating and building to a point that symptoms become evident. The documentation of higher phytoplasma titer in LB-infected palms at earlier stages was documented by Bahder et al. (2020). It was also demonstrated that higher levels of phytoplasma were present earlier in the infection than higher on the trunk (Bahder et al. 2020), supporting the hypothesis that phytoplasmas move from the leaf tissue upon transmission and migrate to the roots and are then pushed systemically throughout the plant. During the latent phase and early symptomatic phase the phytoplasma is moving and replicating at rapid rates while the palm still maintains relatively normal physiological function. However, once the vascular network becomes completely inundated with phytoplasma and physiological function and nutrient transport ceases, the rapid decline of the palm (moderate to late symptoms) causes a subsequent decline in nutrients available to the phytoplasma. Because it is likely not a conducive environment for the survival and replication of the phytoplasma, it thus results in lower levels of phytoplasma as symptoms progress. This is further supported by the absence of phytoplasma cells in leaf tissue (Bahder et al. 2019b), indicating that symptoms are indeed a result of physiological stress and not due to direct damage caused by the phytoplasma itself. The increased vigor of the palms during the latent phase and early symptom onset accounting for higher phytoplasma titers than more heavily symptomatic palms is a possible explanation for this phenomenon; however, there could be other unknown variables contributing. Additionally, in certain instances in which palms are injected, there appears to be an increase in phytoplasma titer. This could either be due to sampling error on the given date or that the OTC-HCl had enough of an effect to maintain proper physiological function, thus allowing more nutrient to be translocated, resulting in further phytoplasma replication and an increase in titer. Although these explanations seem possible, the authors acknowledge that there could be alternative scenarios involving unknown variables that would require further investigation, but that is beyond the scope of this study.

These findings serve as a baseline in order to develop more reliable recommendations to stakeholders. These findings support current recommendations that the best course of action is to remove palms once they are confirmed to be infected and avoid injecting OTC$\mathrm{HCl}$ into palms that already have the phytoplasma, because there is no effect and it potentially could increase disease spread. Future studies will focus on determining the volume and concentration necessary to eliminate symptoms/decline and potentially to eradicate the infection.

\section{Acknowledgments}

The authors thank Dr. Robin Giblin-Davis for his support in conducting this research on the grounds of FLREC and for tolerating the unsightly palms all over the property.

\section{Literature Cited}

Bahder, B.W., and Helmick, E. E. 2018a. Lethal yellowing (LY) of palm. UF/IFAS Extension document PP-222. University of Florida, Gainesville, FL.

Bahder, B.W., and Helmick, E. E. 2018b. Sampling palms for lethal yellowing and Texas phoenix palm decline phytoplasmas. UF/IFAS Extension document ENY-990. University of Florida, Gainesville, FL.

Bahder, B. W., and Helmick, E. E. 2019. Oxytetracycline hydrochloride (OTC$\mathrm{HCl}$ ) application for control of palm phytoplasmas. UF/IFAS EDIS Publication ENY998. University of Florida, Gainesville, FL.

Bahder, B. W., Helmick, E. E., Chakrabati, S., Osorio, S., Soto, N., Chouvenc, T., and Harrison, N. A. 2018. Disease progression of a lethal decline caused by the 16 SrIV-D phytoplasma in Florida palms. Plant Pathol. 67:1821-1828.

Bahder, B. W., Helmick, E. E., and Harrison, N. A. 2017. Detecting and differentiating phytoplasmas belonging to subgroups 16SrIV-A and 16SrIV$\mathrm{D}$ associated with lethal declines of palms in Florida using qPCR and highresolution melt analysis (HRMA). Plant Dis. 101:1449-1454.

Bahder, B. W., Soto, N., Helmick, E. E., Dey, K. K., Komondy, L., Humphries, A. R., Mou, D., Bailey, R., Ascunce, M. S., and Goss, E. M. 2019a. A survey of declining palms (Arecaceae) with 16SrIV-D phytoplasma to evaluate the distribution and host range in Florida. Plant Dis. 103:2512-2519.

Bahder, B. W., Soto, N., Komondy, L., Mou, D., Humphries, A. R., and Helmick, E. E. 2019b. Detection and quantification of the 16SrIV-D phytoplasma in leaf tissue of common ornamental palm species in Florida using qPCR and dPCR. Plant Dis. 103:1918-1922.

Bahder, B. W., Soto, N., Mou, D., Humphries, A. R., and Helmick, E. E. 2020. Quantification and distribution of the 16SrIV-D phytoplasma in the wild date palm, Phoenix sylvestris, at different stages of decline using quantitative PCR (qPCR) analysis. Plant Dis. 104:1328-1334.

Chalak, L., Elbitar, A., Rizk, R., Choueiri, E., Salar, P., and Bové, J. M. 2005. Attempts to eliminate Candidatus phytoplasma phoenicium from infected Lebanese almond varieties by tissue culture techniques combined or not with thermotherapy. Eur. J. Plant Pathol. 112:85-89.

Chung, B. N., and Choi, G. S. 2002. Elimination of aster yellow phytoplasma from Dendranthema grandiflorum by application of oxytetracycline as a foliar spray. Plant Pathol. J. 18:93-97.

Córdova, I., Oropeza, C., Puch-Hau, C., Harrison, N., Collí-Rodríguez, A., Narvaez, M., Nic-Matos, G., Reyes, C., and Sáenz, L. 2014. A real-time PCR assay for detection of coconut lethal yellowing phytoplasmas of group 16SrIV subgroups A, D, and E found in the Americas. J. Plant Pathol. 96: 343-352.

Distabanjong, C., Distabanjong, K., Woo, J. G., and Jang, S. W. 2016. Production of phytoplasma-free plants in sugarcane (Saccharum spp.) using temporary immersion bioreactor. Pages 727-734 in: International Symposia on Tropical and Temperate Horticulture ISTTH2016 1205.

Gribaudo, I., Ruffa, P., Cuozzo, D., Gambino, G., and Marzachi, C. 2007 Attempts to eliminate phytoplasmas from grapevine clones by tissue culture techniques. Bull. Insectol. 60:315-316.

Harrison, N. A., Helmick, E. E., and Elliott, M. L. 2008. Lethal yellowing-type diseases of palms associated with phytoplasma newly identified in Florida, USA. Ann. Appl. Biol. 153:85-94.

Harrison, N. A., Helmick, E. E., and Elliott, M. L. 2009. First report of a phytoplasma-associated lethal decline of Sabal palmetto in Florida, USA. Plant Pathol. 58:792.

Harrison, N. A., Womack, M., and Carpio, M. L. 2002. Detection and characterization of a lethal yellowing (16SrIV) group phytoplasma in Canary Island date palms affected by lethal decline in Texas. Plant Dis. 86:676-681.

Hunt, P., Dabek, A. J., and Schuiling, M. 1974. Remission of symptoms following tetracycline treatment of lethal yellowing-infected coconut palms. Phytopathology 64:307-312.

Kumar, S., Stecher, G., and Tamura, K. 2016. MEGA7: Molecular Evolutionary Genetics Analysis version 7.0 for bigger datasets. Mol. Biol. Evol. 33:1870-1874.

McCoy, R. E. 1972. Remission of lethal yellowing in coconut palm treated with tetracycline antibiotics. Plant Dis. Rep. 56:1019-1021.

McCoy, R. E. 1973. Effect of various antibiotics on development of lethal yellowing in coconut palm. Proc. Fla. State Hortic. Soc. 86:503-506.

McCoy, R. E. 1974. Techniques for treatment of palm trees with antibiotics. Proc. Fla. State Hortic. Soc. 87:537-540.

McCoy, R. E. 1976. Uptake, translocation, and persistence of oxytetracycline in coconut palm. Phytopathology 66:1038-1042.

McCoy, R. E., Carroll, V. J., Poucher, C. P., and Gwin, G. H. 1976. Field control of coconut lethal yellowing with oxytetracycline hydrochloride. Phytopathology 66:1148-1150.

Taloh, A., Dantuluri, D. S., Kumar, G., Padaria, J. C., Kumar, S., and Rao, G. P. 2018. Elimination of 'Candidatus Phytoplasma aurantifolia' from Chrysamthemum morifolium cv. Ajay Orange by application of oxytetracycline by in vivo and in vitro treatments. Phytopathogenic Mollicutes 8:1-7. 